\title{
SELECTION OF AUTOCHTHONOUS SACCHAROMYCES AND NON-SACCHAROMYCES YEASTS STRAINS ACCORDING TO THEIR EXTRACELLULAR ENZIMATIC ACTIVITY
}

\author{
E. Brîndușe ${ }^{1 *}$, M. Ion ${ }^{1}$, C.L. Nedelcu ${ }^{1}$, \\ L. Fîciu ${ }^{1}$ and A. Pantazi ${ }^{1}$ \\ 1 Research and Development Institute for Viticulture and Enology, Valea \\ Călugărească, Romania \\ * Corresponding author, e-mail: elabrinduse@gmail.com
}

\begin{abstract}
The aim of the present study was to investigate the production of extracellular enzymes in a number of twenty six autochtonous Saccharomyces and nonSaccharomyces strains selected in Dealu Mare region for wine production. The strains were screened for the production of extracellular b-glucosidase, esterase, pectinase and protease activity by inoculation the yeast strains onto selective media. All Saccharomyces tested strains showed at least two enzymatic activities while nonSaccharomyces strains showed activity at least for one enzyme. The weakest activity was recorded in case of $\beta$-glucosidase. Most of the tested strains exhibit more or less intense activity for polygalacturonase/pectinase and protease. This study put into evidence the potential of autochtonous and especially of non-Saccharomyces strains as source of production of secondary compounds which can play an important role in improving the quality of wines.
\end{abstract}

Keywords: fermentation, enzymatic activity, selection, Saccharomyces, non-Saccharomyces.

\section{INTRODUCTION}

In recent years, there has been growing the interest in using autochthonous Saccharomyces and non-Saccharomyces strains in controlled double or multistarter cultures to improve wine quality (Strauss et al., 2001; Jolly et al., 2014; Dutraive et al., 2019).Several studies have pointed out that non-Saccharomyces yeasts produce and secrete several enzymes (esterases, glycosidases, lipases, b-glucosidases, proteases, cellulases, etc.) that could have a positive influence on the characteristics of the wine, mainly on the varietal aroma (Charoenchai et al., 1997). In Romania, until now, there has been a real interest and results in the isolation and oenological characterization only of yeast strains belonging to the genus Saccharomyces, there are no concerns regarding the screening of non-Saccharomyces species, as well as the use of mixed cultures in the vinification process. The objective of this study was to evaluate the extracellular enzymatic activity of 26 autochthonous Saccharomyces and non-Saccharomyces strains selected in Dealu Mare region for wine production. On the basis of the results, the best strains will be used in double or sequential culture aiming to improve the characteristics of resulted wines.

\section{MATERIALS AND METHODS}

Twenty six yeast strains belonging toSaccharomyces, Candida and Debaryomyces genus were screened for the production of extracellular b-glucosidase, esterase, pectinase and protease 
activity. All strains were isolated and selected from the vineyard of Valea Călugărească viticultural centre, from the grape surface and from various phases of must fermentations and identified by means of conventional morphological, physiological and biochemical procedures and also through molecular biology analysis (data reported elsewhere). Cultures were maintained in the microorganisms collection of the Research Institute for Viticulture and Oenology Valea Călugărească on Yeast Extract Peptone Glucose agar medium, on slants under paraffin oil and subcultivated every 6 months on the same medium. In order to screen the selected wine yeasts for the extracellular enzymatic activity the yeast strains were inoculated onto selective media. The screening for $\beta$-glucosidase activity was perform by inoculation of the yeast strains on medium containing (g/L): Yeast Nitrogen Base, 6.7; cellobiose, as carbon source 10 and agar, 20. pH of the medium was adjusted at 5.5 (Fernanda Gaensly et al., 2015). Extracellular esterase activity was determined by using a medium with the following composition (g/L): peptone, $10 ; \mathrm{NaCl}, 5 ; \mathrm{CaCl}_{2} \mathrm{x}_{2} \mathrm{H}_{2} \mathrm{O}, 0.1$; Tween 80 (polyoxyethylene sorbitan monooleate), 10 and agar, 20, pH 6.8). Yeasts with enzymatic activity hydrolyze the substrate and a precipitate (opaque halo) is visible around the colonies (Slifkin, 2000).

The protease activity assay was carried out on medium containing $(\mathrm{g} / \mathrm{L})$ : yeast extract, 3 ; malt extract, 3; peptone, 5; glucose, 10; $\mathrm{NaCl}$, 5; agar, 15. In a separate bottle, an equal volume of skimmed milk dissolved in sterile water was prepared. After sterilization, the two solutions were mixed and distributed into sterile Petri dishes. The presence of a clear zone around the inoculum indicated the protease activity (Comitini et al., 2011).

Polygalacturonase/pectinase activity was determined as described by Strauss et al. (2001) with some modifications. Yeasts were cultivated on polygalacturonate agar medium containing (g/L): polygalacturonic acid, 12.5; potassium phosphate, 6.8; Yeast Nitrogen Base, 6.7; glucose, 10; and agar, 20. After colonies growth, plates were flooded with hexadecyltrimethylammonium bromide $(10 \mathrm{~g} / \mathrm{L})$. Colonies showing clear halo around were identified as positive. Yeasts suspensions after $24 \mathrm{~h}$ of culture (A580 $=0.5$, corresponding to a cell concentration of $10^{6} / \mathrm{ml}$ ) were used for inoculation (after P. Buzzini and A. Martini, 2002).Inoculation of the yeast strain was performed on the surface of the sterilized medium by autoclaving at $120^{\circ} \mathrm{C}$ for $15 \mathrm{~min}$. (from place to place).The cultures were incubated at $28^{\circ} \mathrm{C}$ for 5-7 days. For each analyzed strain, 3 repetitions were performed. Observations were made daily on cell growth. Yeasts with enzymatic activity hydrolyze the substrate.

The assessment of the degree of production of extracellular enzymes during the vinification process was made by measuring the colonies and establishing the degree of growth after 120 hours. The interpretation of the results was done as follows (Table 1):

Table 1. Interpretation of the results concerning the degree of enzymatic activity

\begin{tabular}{|l|l|}
\hline \multicolumn{1}{|c|}{ Degree of colony growth } & \multicolumn{1}{c|}{ Results } \\
\hline $0 \mathrm{~mm}$ & No enzymatic activity \\
\hline $0.10-0.20 \mathrm{~mm}$ & Very low activity \\
\hline $0.21-0.30 \mathrm{~mm}$ & Low activity \\
\hline $0.31-0.40 \mathrm{~mm}$ & Intense activity \\
\hline$>0.40 \mathrm{~mm}$ & Very intense activity \\
\hline
\end{tabular}

\section{RESULTS AND DISCUSSIONS}

Both Saccharomyces and non-Saccharomyces yeasts strains showed extracellular enzymatic activity for at least two enzymes (Table 2). 
Table 2. Characterization of extracellular enzymatic activity of Saccharomyces yeasts strains

\begin{tabular}{|c|c|c|c|c|}
\hline \multirow{2}{*}{$\begin{array}{c}\text { Saccharomyces } \\
\text { cerevisiae } \\
\text { (Code) }\end{array}$} & \multicolumn{4}{|c|}{ Extracellular enzymatic activity } \\
\hline & $\beta$ Glucozidase & Esterase & Protease & Pectinase \\
\hline 21 & + & - & +++ & + \\
\hline 23 & ++ & ++ & - & - \\
\hline 24 & ++ & +++ & + & + \\
\hline 26 & - & +++ & ++ & + \\
\hline 28 & - & + & ++++ & + \\
\hline 29 & + & +++ & ++++ & ++ \\
\hline 30 & ++ & +++ & + & + \\
\hline 33 & ++ & + & - & ++ \\
\hline 34 & + & + & ++ & ++ \\
\hline 35 & + & + & ++++ & ++ \\
\hline 36 & + & +++ & ++++ & - \\
\hline 37 & + & + & ++++ & ++ \\
\hline 75 & + & ++++ & ++++ & - \\
\hline 76 & + & ++++ & ++++ & ++ \\
\hline 77 & - & +++ & + & ++ \\
\hline 79 & + & +++ & + & ++ \\
\hline 137 & - & ++ & +++ & - \\
\hline
\end{tabular}

Legend: - no activity; + very low activity; ++ low activity; +++ intense activity; ++++ very intense activity

A similar study perform by González, J.A. et al. (2004), aiming to evaluate the variability of enzymatic activities during the wine fermentation using 15 yeast strains, revealed that all the non-Saccharomyces strains tested showed at least one enzymatic activity, while Saccharomycesstrains showed only two enzimatic activities.

Very low and low activity was registered, in case of Saccharomyces cerevisiae strains, for the enzymes $\beta$ glucosidase and pectinase, while for the esterase and protease was registered intense and very intense activity in a high percentage.

Concerning $\beta$ glucosidase activity, similar results were obtained by Fia G. et al. (2005). Very weak or no detectable hydrolytic activity was observed in case of Saccharomyces cerevisiae strains, while non- Saccharomyces strains exhibited different degree of $\beta$ glucosidase activity.

In a study performed by Rosi I, et al. (1994), 317 strains, representing 20 species of yeasts, were screened for the presence of $\beta$-glucosidase activity. All the strains of the species Debaryomyces castellii, Debaryomyces hansenii, Debaryomyces polymorphus, Kloeckera apiculata and Hansenula anomala showed $\beta$-glucosidase activity, but only one of the 153 strains belonging to Saccharomyces cerevisiae.

In our study, 13 yeasts strains representing $76.47 \%$ showed $\beta$ glucosidase activity. In case of 9 strains (52.94\%) the activity was very low (colony increases between 1.0 and 2.0 
$\mathrm{mm}$ ) and for 4 strains the activity was low (colony increases between 2.1 and $3.0 \mathrm{~mm}$ ); 5 of the strains (29.41\%) showed very low pectinase activity and 8 strains $(47.06 \%)$ showed low activity;16 strains (94.12\%) showed esterase activity, in case of 7 of them $(41.18 \%)$ the activity being very intense; 15 strains (88.24\%) exhibited protease activity, in case of 7 of the strains (41.18\%) the activity being very intense (Table 3; Figure 1,2).

Table 3. The intensity of extracellular enzymatic activity registered by Saccharomyces yeasts strains

\begin{tabular}{|l|l|l|l|l|l|l|l|l|l|l|l|l|}
\hline \multicolumn{1}{|c|}{ Enzyme } & \multicolumn{2}{|c|}{$\begin{array}{c}\text { Positive } \\
\text { strains }\end{array}$} & \multicolumn{2}{|c|}{ No activity } & \multicolumn{2}{|c|}{$\begin{array}{l}\text { Very low } \\
\text { activity }\end{array}$} & \multicolumn{2}{|c|}{$\begin{array}{c}\text { Low } \\
\text { activity }\end{array}$} & \multicolumn{2}{|c|}{$\begin{array}{c}\text { Intense } \\
\text { activity }\end{array}$} & \multicolumn{2}{|c|}{$\begin{array}{c}\text { Very } \\
\text { intense } \\
\text { activity }\end{array}$} \\
\cline { 2 - 16 } & Nr. & $\%$ & Nr. & $\%$ & Nr. & $\%$ & Nr. & $\%$ & Nr. & $\%$ & Nr. & $\%$ \\
\hline$\beta$ Glucozidase & 13 & 76.47 & 4 & 23.53 & 9 & 52.94 & 4 & 23.53 & 0 & & 0 & \\
\hline Esterase & 16 & 94.12 & 1 & 5.88 & 5 & 29.41 & 2 & 11.76 & 7 & 41.18 & 2 & 11.76 \\
\hline Protease & 15 & 88.24 & 2 & 11.76 & 4 & 23.53 & 2 & 11.76 & 2 & 11.76 & 7 & 41.18 \\
\hline Pectinase & 13 & 76.47 & 4 & 23.53 & 5 & 29.41 & 8 & 47.06 & & & & \\
\hline
\end{tabular}

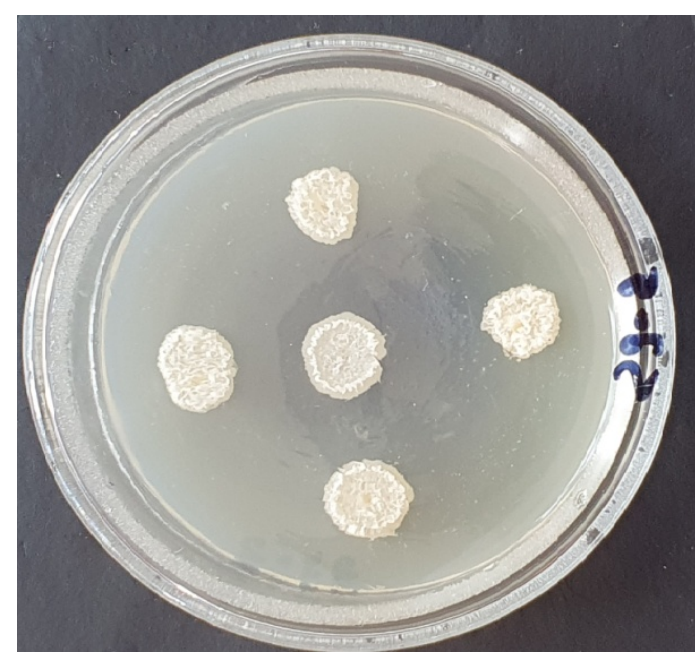

Figure 1. Strain yeast with intense esterase activity

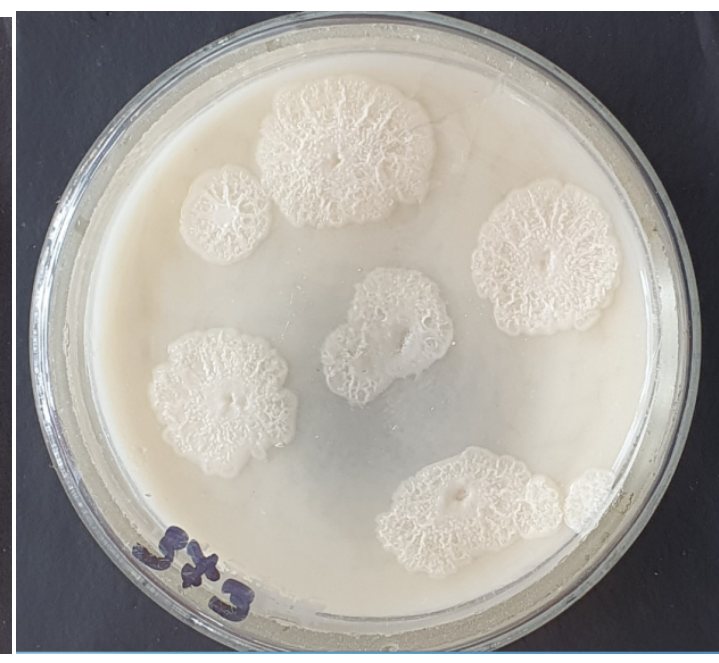

Figure 2. Strain yeast with intense pretease activity

Most of the non-Saccharomyces yeasts strains taking into study showed very low and low enzyme activity with some exceptions.

Candida magnoliae strains 5 and Debaryomyces chevallieri strain 20b were noted by very intense protease activity, while Candida utilis strain 56 showed a very intense esterase activity (Table 4).

Similar results were reported by Charoenchai et al. (1997) following the researches concerning the effect of nitrogen sources on the production of extracellular proteases by non-Saccharomyces wine yeasts. From 26 yeast strains, protease activity was observed in strains of Candida pulcherrima, K. apiculata and Pichia anomala.

Proteolytic activity of non-Saccharomyces strains belonging to Candida and Debaryomyces genus was reported by Strauss M.L.A. et al. (2001). 
Table 4. Characterization of extracellular enzymatic activity of non - Saccharomyces yeasts strains

\begin{tabular}{|c|c|c|c|c|c|}
\hline \multirow{2}{*}{$\begin{array}{l}\text { Yeast strain } \\
\text { (Code) }\end{array}$} & \multirow[t]{2}{*}{ Species } & \multicolumn{4}{|c|}{ Extracellulat enzymatic activity } \\
\hline & & $\beta$ Glucozidase & Esterase & Protease & Pectinase \\
\hline 1 & Candida lusitaniae & + & + & + & - \\
\hline 5 & Candida magnoliae & + & + & ++++ & + \\
\hline 6 & Candida magnoliae & - & + & + & + \\
\hline 7 & Candida magnoliae & + & + & + & - \\
\hline 56 & Candida utilis & + & ++++ & + & - \\
\hline 57 & Candida utilis & + & + & ++ & + \\
\hline 136 & Candida sphaerica & + & + & ++ & - \\
\hline 241 & Candida pelliculosa & - & ++ & + & + \\
\hline $20 \mathrm{~b}$ & $\begin{array}{l}\text { Debaryomyces } \\
\text { chevallieri }\end{array}$ & - & ++ & +++ & - \\
\hline
\end{tabular}

Legend: - no activity; + very low activity; ++ low activity; +++ intense activity; ++++ very intense activity.

On the basis of these results, the best strains will be used in double or sequential culture aiming to improve the characteristics of resulted wines, respectively to enhance the aroma and flavor properties of wines (strains which showed $\beta$ Glucozidase and esterase activity), to increase juice extraction from grapes, improve wine clarification and facilitate wine filtration and stabilization of must and wine (strains which showed protease and pectinase activity).

\section{CONCLUSION}

This study put into evidence the potential of autochtonous and especially of nonSaccharomyces strains as source of production of secondary compounds which can play an important role in improving the quality of wines. All Saccharomyces tested strains showed at least two enzymatic activity while non-Saccharomyces strains showed activity only for one enzyme. The lowest activity was recorded in case of $\beta$-glucosidase. Most of the tested strains exhibit more or less intense activity for polygalacturonase/pectinase and protease.

\section{ACKNOWLEDGEMENTS}

This study was funded by Ministry of Agriculture and Rural Development, Romania, within the Sectorial Plan for Research and Development-ADER 2022, Project 712 "Selection, conservation and exploitation of the autochtonous yeasts biodiversity".

\section{REFERENCES}

1. Buzzini P., Martini A., (2002). Extracellular enzymatic activity profiles in yeast and yeast-like strains isolated from tropical environments, Journal of Applied Microbiology, 93, 1020-1025.

2. Charoenchai, C., Fleet, G.H., Henschke, P.A., Todd, B.E.N., (1997), Screening of non-Saccharomyces wineyeasts for the presence of extracellular hydrolytic enzymes. Australian Journal of Grape Wine Research, 3,2 8.

3. Comitini F., Gobbi M., Domizio P., Romani C., Lencioni L., Mannazzu I., Ciani M., (2011), Selected nonSaccharomyces wine yeasts in controlled multistarter fermentations with Saccharomycescerevisiae, FoodMicrobiology, 28, 873-882. 
4. Dutraive O., Benito S., Fritsch S., Beisert B., Patz C.-D., Rauhut D., (2019),Efect of Sequential Inoculation with Non-Saccharomyces and Saccharomyces Yeasts on RieslingWine Chemical Composition, Fermentation 2019, 5, 79; doi:10.3390/fermentation 5030079.

5. Fernanda G., Bruna C. A., Gildo Almeida da Silva, Geraldo P., Tania M. B.,(2015), Autochthonous yeasts with $\beta$ glucosidaseactivity increase resveratrol concentration duringthe alcoholic fermentation of Vitis labrusca grape must, Journal of Functional Foods, 19, 288-295.

6. Fia G., Giovani G., Rosi I., (2005), Study of $\beta$-glucosidase production by wine-related yeasts duringalcoholicfermentation. A new rapid fluorimetric method to determine enzymatic activity, J. Appl. Microbiol,, 99,(3), 509-517.

7. Jolly N.P., Varela C., Pretorius I. S., (2014), Not your ordinary yeast: non-Saccharomyces yeasts in wine production, FEMS Yeast Res., 14, 215-237.

8. Rosi I., Vinella M., Domizio P., (1994), Characterization of $\beta$-glucosidase activity in yeasts of oenological origin. Journal of Applied Microbiology, vol. 77, 519-527.

9. Slifkin, M., (2000), Tween 80 opacity test responses of various Candida species. Journal of Clinical Microbiology, 38, 4626-4628.

10. Strauss M.L.A., Jolly N.P., Lambrechts M.G., Rensburg P., (2001), Screening for the production of extracellular hydrolytic enzymes by non-Saccharomyces wine yeasts, Journal of Applied Microbiology, 91, 182-90. 